\title{
Enhancing Thermal and Mechanical Properties of UHMWPE/HA Composite as Tibial Tray
}

\author{
Yusuf Bramastya Apriliyanto ${ }^{1}$, Sri Sugiarti ${ }^{1{ }^{*}}$, and Sulistioso Giat Sukaryo ${ }^{2}$ \\ ${ }^{1}$ Department of Chemistry, Bogor Agricultural University, Chemistry Building, Wing 1, $3^{\text {rd }}$ Floor, \\ Tanjung St., IPB Darmaga Campus, Bogor 16680, Indonesia \\ ${ }^{2}$ Center for Science and Advanced Material Technology, National Nuclear Energy Agency (PSTBM-BATAN), \\ Puspiptek St., Tangsel-Banten 15314, Indonesia
}

${ }^{*}$ Corresponding author:

tel: $+62-251-8624567$

email: sri.sw07@gmail.com

Received: March 11, 2019

Accepted: May 24, 2019

DOI: $10.22146 /$ ijc. 44086

\begin{abstract}
A bearing material in an artificial knee joint has to have good thermal and mechanical properties to prevent wear in order to be used as a tibial tray. Despite its wellknown good properties, ultrahigh molecular weight polyethylene (UHMWPE) still needs to be modified to enhance its physical strength in its use in artificial joints. In this research, composites made from UHMWPE and hydroxyapatite (HA) were prepared by mechanical alloying and hot press method and their thermal and mechanical properties were modified using gamma rays. The composites were prepared using various $H A$ loading ratios and irradiated using gamma rays at doses of $0,25,50$, and $75 \mathrm{kGy}$. The effects of HA loading and gamma irradiation on thermal and mechanical properties were studied by various methods. The results showed that the addition of HA enhanced the hardness of UHMWPE by 8-15\% and the maximum stress up to 38\%. Gamma irradiation enhanced the crystallinity by 113-172\%, the melting point by 0.6-0.7\%, and decreased the break elongation of composites by 23-48\%. Addition of polyvinyl alcohol $(5 \% \mathrm{w} / \mathrm{w})$ in composites reduced their rigidity by $16-47 \%$ and hardness by 3-9\%.
\end{abstract}

Keywords: tibial tray; UHMWPE/HA composites; physical properties; irradiation, biomaterials

\section{- INTRODUCTION}

Joints are part of the body that are susceptible to damage caused by inflammation (osteoarthritis) and mechanical impact in case of accidents. One way that can be made to restore the normal function of a joint is by joint replacement surgery (arthroplasty). The most commonly replaced joints are knee and hip joints (>90\%). Statistically, the annual incidence rates of total knee replacement are higher compared to other artificial joints [1-2]. The artificial knee joint consists of the femoral component, the tibial tray, and the tibial component. Biomaterials used as a tibial tray must have good mechanical strength due to its function as a bearing material that connects the femur and tibia bones. In addition, implants used as artificial joints must also have a long lifetime [3]. Since it has to be placed within the corrosive environment of body fluids, it must be composed of non-biodegradable bioinert materials [4].
Ultrahigh molecular weight polyethylene (UHMWPE) is a polymer having good mechanical properties (e.g., resistant to wear, tear, abrasion, impact, chemicals) and good biocompatibility. UHMWPE has long been used as a bearing material in artificial knee joints because it has good physical properties [5]. However, in its use as a tibial tray, continuous pressure and friction can lead to wear of the material, shortening the lifetime of the artificial knee joints [6]. UHMWPE particles released due to wear may also cause inflammation in surrounding tissues leading to osteolysis [7]; therefore, further efforts are needed to enhance the physical properties of UHMWPE as a tibial tray. Ionizing radiation (e.g., gamma rays) is commonly used to initiate cross-linking between the polymer chains, and this approach successfully enhances the physical properties of many polymers [8]. However, oxidation related to 
radical promoted reactions limits the use of this approach [9]. Oxidation especially occurs in large dose irradiations; thus, an antioxidant agent is needed to inhibit oxidation without limiting the cross-linking processes [10].

A polymer can also be modified to make a composite with improved physical properties by adding fillers into the matrix [11]. Some UHMWPE-based composites with improved properties have been reported in the literature, for instance UHMWPE-graphene oxide [12], UHMWPEcarbon fiber [13], UHMWPE-carbon nanotubes (CNT) [14], UHMWPE-HA [15-17], UHMWPE- $\mathrm{Al}_{2} \mathrm{O}_{3}$ [18], and even hybrid bio-composites of UHMWPE-HA- $\mathrm{Al}_{2} \mathrm{O}_{3^{-}}$ CNT [19]. Hydroxyapatite (HA) belongs to a class of bioactive ceramics that has high bio-affinity and biocompatibility. These properties arise from its chemical composition similarity with bone [20]. Therefore, hydroxyapatite is regularly used to improve the biocompatibility of an implant [21].

Moreover, the addition of hydroxyapatite into a polymer matrix can also increase its hardness and crystallinity [22]. Considering the importance of UHMWPE modification used for bearing material, UHMWPE/HA composites were prepared with and without the addition of polyvinyl alcohol (PVA) by mechanical alloying and hot press method and their thermal and mechanical properties were modified using gamma rays. PVA was used because of its biocompatibility, high lubricity, and cushioning properties [23].

\section{- EXPERIMENTAL SECTION}

\section{Materials}

UHMWPE powder (molecular weight 3 to $6 \times$ $10^{6} \mathrm{~g} \mathrm{~mol}^{-1}$ ) and PVA powder (molecular weight 8.9 to 9.8 $\times 10^{4} \mathrm{~g} \mathrm{~mol}^{-1}$ ) were purchased from Sigma Aldrich. Nanometer-sized HA (10 to $20 \mathrm{~nm}$ ) was obtained from the Centre of Application Isotopes and Radiation (PAIR BATAN, Jakarta) that had been synthesized from Lates calcarifer fish.

\section{Instrumentation}

Instruments used in the mechanical alloying of UHMWPE/HA composites were a PW 700i high energy mill supported with a stainless steel vial and balls, and a Hydraulics Pj16h hot press apparatus. The products were characterized by using a Shimadzu XD 610X-ray diffractometer (XRD), a JEOL JED-2300 scanning electron microscope-energy dispersive $\mathrm{X}$-ray spectrometer (SEM-EDX), and a Shimadzu IRPrestige21 Fourier transform infrared spectrometer (FTIR). The composites were irradiated by using the gamma irradiator at the Centre of Application Isotopes and Radiation; prior to analyzing their hardness, tensile strength, and thermal properties by using a Zwick ISO/R 868 Shore A hardness tester, a Toyoseiki tensile tester, and a Perkin Elmer differential scanning calorimeter (DSC).

\section{Procedure}

\section{Composites preparation}

UHMWPE/HA composites were prepared by mixing UHMWPE and HA powder with HA loading ratios of 5,10 , and $15 \% \mathrm{w} / \mathrm{w}$. PVA $5 \% \mathrm{w} / \mathrm{w}$ was also added into some of the powder mixtures while maintaining weight percentage of HA. Each of these powder mixtures had a total weight of $12 \mathrm{~g}$. The prepared powder mixture was placed into a stainless steel vial, then stainless steel balls were added into the vial. The weight ratio between the powder and balls was fixed at 1:8. The mechanical alloying was performed for $90 \mathrm{~min}$ by using the PW 700i high energy mill at $1000 \mathrm{rpm}$. Each of these produced composites was molded to make films with a dimension of $15 \mathrm{~cm} \times 15 \mathrm{~cm} \times 0.05 \mathrm{~cm}$ using the hot press apparatus operated at $190{ }^{\circ} \mathrm{C}$ and $140 \mathrm{~kg} \mathrm{~cm}^{-2}$ for $5 \mathrm{~min}$, then the hot films were cooled in a cold press apparatus for $5 \mathrm{~min}$.

\section{Composites characterization and irradiation}

Composite films containing the lowest and highest HA content (UHMWPE + 5\% HA, UHMWPE $+15 \%$ HA, UHMWPE + 5\% HA + 5\% PVA, and UHMWPE + $15 \% \mathrm{HA}+5 \%$ PVA) as well as the controls (pure UHMWPE, HA, and PVA) were characterized by using $\mathrm{XRD}$ at $2 \theta$ angle starting from $5^{\circ}$ to $55^{\circ}$. Composite films containing the highest HA content (UHMWPE + 15\% HA and UHMWPE + 15\% HA + 5\% PVA) were then analyzed for their surface morphology by using SEM- 
EDX. After characterization, all composite films were irradiated to modify their properties. Irradiated films were prepared by exposing the films over gamma rays produced from $\mathrm{Co}^{60}$ isotope. Composite films were irradiated at doses of $0,25,50$, and $75 \mathrm{kGy}$ at $8 \mathrm{kGy} \mathrm{h}^{-1}$ dose rate. Irradiation was conducted in a chamber under atmospheric conditions.

\section{Thermal and mechanical properties tests}

Thermal properties of composites with the lowest HA content (UHMWPE + 5\% HA: 0, 25, and $75 \mathrm{kGy}$ ) were investigated by using DSC under nitrogen gas atmosphere $\left(20 \mathrm{cc} \mathrm{min}^{-1}\right)$. The operating temperature ranged from $25^{\circ} \mathrm{C}$ to $200{ }^{\circ} \mathrm{C}$ with a heating rate of $20^{\circ} \mathrm{C}$ $\mathrm{min}^{-1}$. The peak of the endotherm plots indicated the melting points, while crystallinity was calculated by comparing the enthalpy of fusion of the composites with the enthalpy of fusion of $100 \%$ crystalline polyethylene $\left(292.5 \mathrm{~J} \mathrm{~g}^{-1}\right)$ [5]. The hardness of all the composites was measured by using the Zwick ISO/R 868 Shore A tester; the results were then converted into Shore D units. Tensile tests were also applied to check the maximum stress and break elongation before and after irradiation. All of the mechanical tests were repeated three times for each composite. The effect of gamma radiation on polymer chains structure was observed by estimating the oxidation index (OI) and vinylene index (VI) of the composites with the lowest HA contents (UHMWPE +
5\% HA: 0, 25, 50, and $75 \mathrm{kGy}$ ) by using FTIR. OI and VI values were calculated as follows $[6,9]$.

$\mathrm{OI}=\left|\frac{\mathrm{I}_{1720}}{\mathrm{I}_{2022}}\right| ; \mathrm{VI}=\left|\frac{\mathrm{I}_{965}}{\mathrm{I}_{2022}}\right|$

$\mathrm{I}_{1720}$ is the absorption intensity around $1720 \mathrm{~cm}^{-1}$ for the carbonyl group, $\mathrm{I}_{965}$ is the absorption intensity around $965 \mathrm{~cm}^{-1}$ for vinylene group (mainly transvinylene), and $\mathrm{I}_{2022}$ is the absorption intensity around $2022 \mathrm{~cm}^{-1}$ for polyethylene vibration (amorphous and crystalline).

\section{- RESULTS AND DISCUSSION}

\section{Characterization of Composites}

Composites are materials formed by combining two or more substances that are physically bound together, producing materials with different properties from their individual components. Physically bound means that each component remains separate and distinct inside a composite [16]. Each compound has a distinctive $\mathrm{X}$-ray diffraction pattern; therefore, it can be utilized for qualitative analysis of a composite by comparing the diffraction pattern of the composite with its constituent compounds. If the diffraction pattern of the starting materials is lost or changed and there is a different diffraction pattern, this is an indication that there has been a chemical reaction producing a new material rather than a composite. Fig. 1 shows the diffractograms
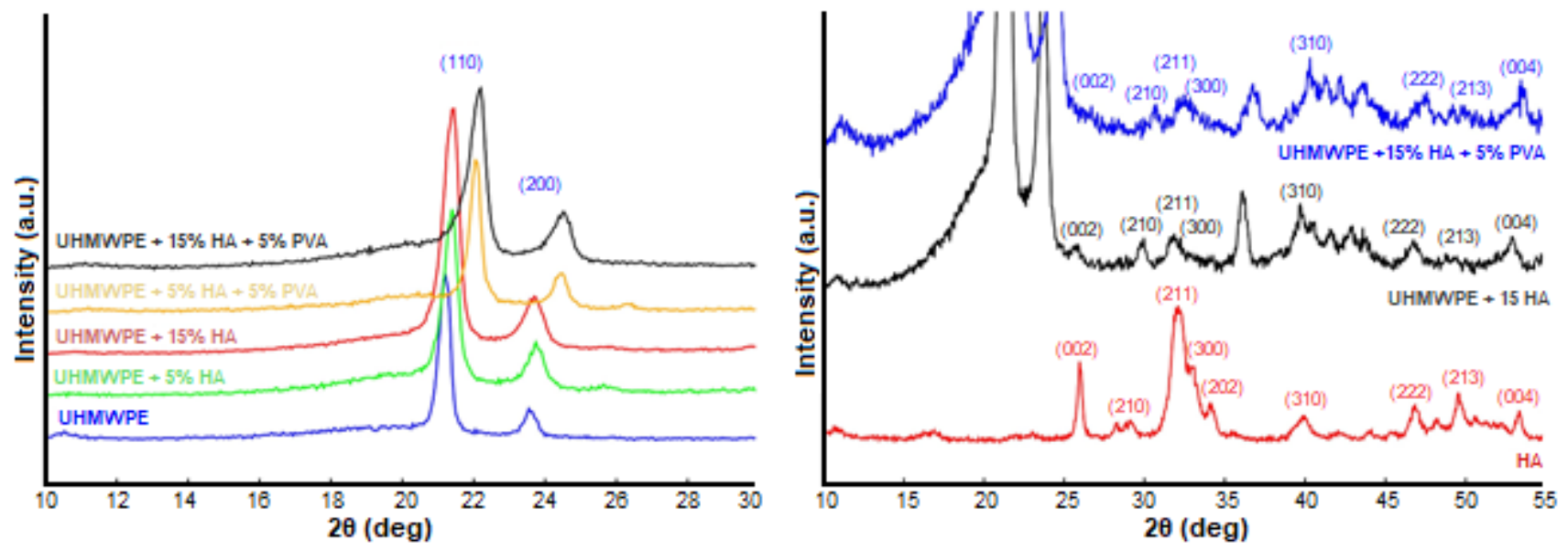

Fig 1. X-ray diffraction pattern of composites. UHMWPE identification in composites (left panel) and identification of HA in composites (right panel) 
of UHMWPE/HA composite with various HA loading ratios as well as its constituent compounds. Using these diffractograms, UHMWPE lattice parameters were calculated with the Joint Committee database on Powder Diffraction Standards (JCPDS) as a reference. The lattice parameters of UHMWPE are reported in Table 1.

The presence of UHMWPE in composites was identified by analyzing the diffraction patterns (Fig. 1) and comparing the lattice parameters in the UHMWPE sample with composite samples (Table 1). The emergence of peaks at almost the same $2 \theta$ angles and similar diffraction pattern on composites and UHMWPE can be clearly seen in the left panel of Fig. 1. Table 1 shows that UHMWPE lattice parameters on composites also have values close to UHMWPE lattice parameters. This indicates that there is a UHMWPE compound in the produced composites. However, the peaks of composites diffraction were slightly shifted to larger $2 \theta$ angle. This is caused by the milling process during composites preparation. The high energy ball milling process decreased the size of materials, as evidenced by the volume of UHMWPE unit cells (see Table 1).

HA in composites was also identified the same way, using samples with the highest HA content (Fig. 1, right panel). Those diffraction patterns show that the composites have diffraction peaks at $2 \theta$ angles similar to the diffraction peaks of HA. Since the HA content in composites is quite small $(15 \% \mathrm{w} / \mathrm{w})$, the intensity of the diffraction peaks is low. In addition, the HA lattice parameters and volume of HA unit cells in the composites also have values close to the initial HA (reported in Table 2) indicating that there is $\mathrm{HA}$ compound in the composites. The case of the composites with PVA addition will be discussed further in the next section. Based on the above identification of the matrix (UHMWPE) and the filler (HA), it was concluded that UHMWPE-HA composites had been successfully formed from physically bound individual components.

The formation of composites can also be verified by looking at the SEM micrographs presented in Fig. 2 . Fig. 2 shows that the individual components remain separate within the finished structures, and they can be distinguished by their physical appearances. Moreover, it can be seen from Fig. 2 that micro and sub-micrometer sized filler was randomly distributed over the polymer matrix. Although high energy ball milling technique was applied, dispersed nano-HA composites were difficult to obtain [18]. Since nano-HA has very high surface area and different functional groups (different polarity properties)

Table 1. Lattice parameters of orthorhombic unit cells of UHMWPE

\begin{tabular}{lcccc}
\hline Sample & $\mathrm{a}(\AA)$ & $\mathrm{b}(\AA)$ & $\mathrm{c}(\AA)$ & $\mathrm{V}\left(\AA^{3}\right)$ \\
\hline UHMWPE & 7.4179 & 4.9336 & 2.5425 & 93.0477 \\
UHMWPE + 5\% HA & 7.3866 & 4.9115 & 2.5416 & 92.2091 \\
UHMWPE + 15\% HA & 7.4020 & 4.8976 & 2.5372 & 91.9795 \\
\hline
\end{tabular}

Table 2. Lattice parameters of hexagonal unit cell of HA

\begin{tabular}{lccc}
\hline Sample & $\mathrm{a}(\AA)$ & $\mathrm{c}(\AA)$ & $\mathrm{V}\left(\AA^{3}\right)$ \\
\hline HA & 9.3539 & 6.8797 & 521.2994 \\
UHMWPE + 15\% HA & 9.3507 & 6.8805 & 520.9964 \\
\hline
\end{tabular}

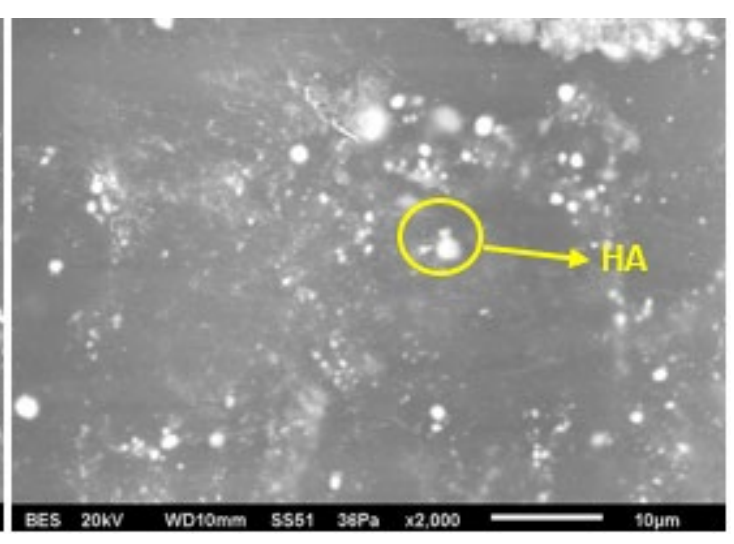

Fig 2. SEM micrographs of UHMWPE + 15\% HA composite with $1000 \times$ (left panel) and $2000 \times$ (right panel) magnification 
are present in HA and UHMWPE, agglomeration of HA particles is favored over dispersion. The agglomerated HA particles can be seen in Fig. 2 and from relatively high standard deviation value (SD) of the presence of elements ( $\mathrm{Ca}, \mathrm{P}$, and $\mathrm{O}$ ) at some different points over the surface obtained from EDX analysis (SD ranging from 0.4 to 6.5).

\section{The Effect of Gamma Irradiation on Thermal Properties}

Radiation dose affects melting point and fusion enthalpy of UHMWPE/HA composites. Melting point and fusion enthalpy of composites increased with increasing radiation dose (see Fig. 3). This increment corresponds to the increased crystallinity of composite presented in Fig. 4. Melting point depends on the size and perfection of a crystal, the larger and more perfect a crystal, the higher the melting point [5]. Therefore, the

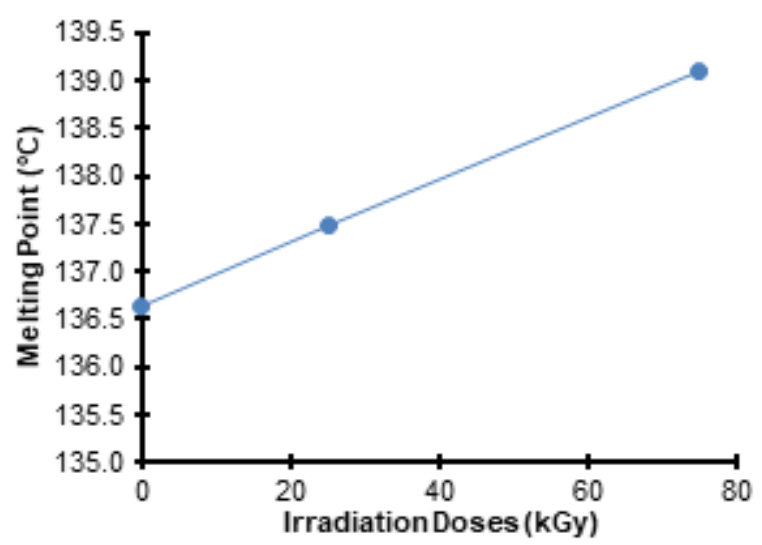

Fig 3. Melting point (left panel) and enthalpy of fusion of UHMWPE + 5\% HA composites (right panel) plotted as a function of irradiation dose

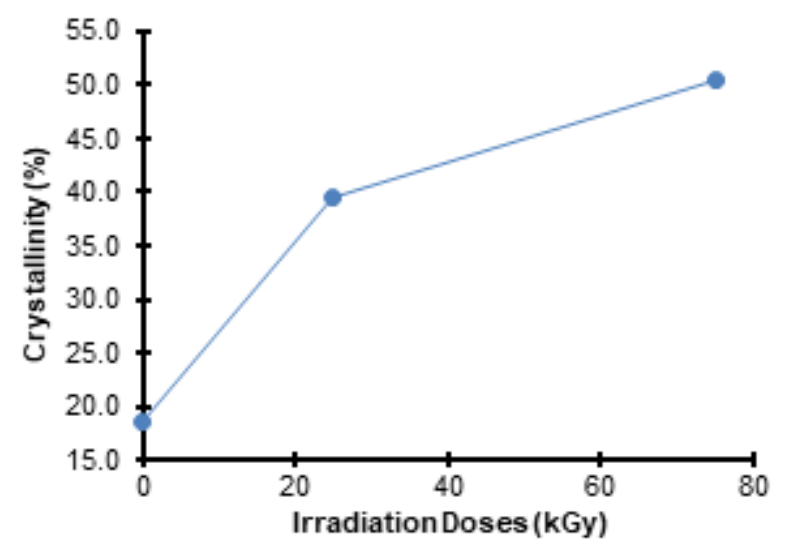

Fig 4. Crystallinity of UHMWPE + 5\% HA composites plotted as a function of irradiation dose energy required to melt the crystalline structure is higher than that of the amorphous particles [21]. In addition, the increment of melting point and fusion enthalpy could be regarded as an indication of cross-linking. A high cross-link level will decrease the degree of freedom between polymer chains; thus, the energy required to convert a solid phase into a liquid phase will even be higher. The higher the degree of crystallinity and crosslink level, the higher the energy required to convert the composite from solid to liquid [5].

\section{The Effect of Gamma Irradiation on Hardness}

The results of the composite hardness test (Fig. 5) show that their hardness was directly proportional to the radiation dose. Pure UHMWPE ( $0 \%$ HA) hardness values are in the range of 42 to 43 Shore $\mathrm{D}$, while composites hardness values are in the range of 46 to 50 Shore $\mathrm{D}$. The

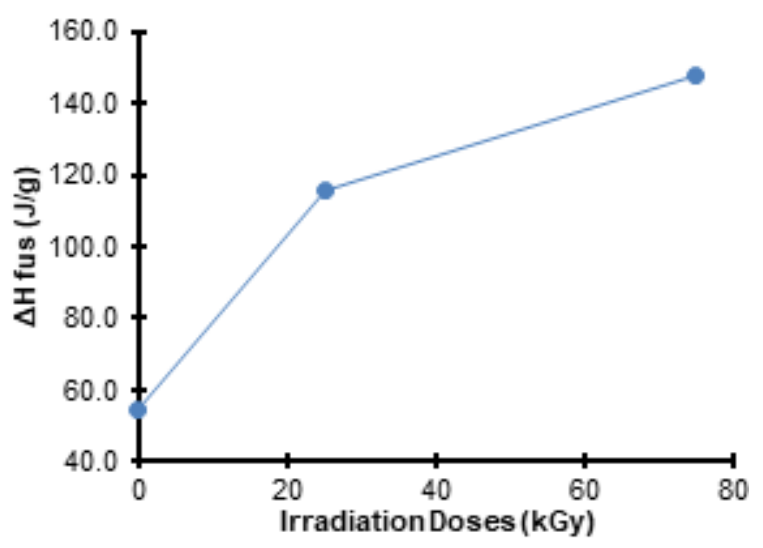


hardness of composites is higher than pure UHMWPE. The hardness of composites is also higher than irradiated UHMWPE (0-150 kGy) reported by Sukaryo et al. [8] where the hardness ranged from 38 to 46 Shore D. The hardness values also increased with increasing HA content in the composites (Fig. 5). HA is a bioactive ceramic material whose structure and strength are similar to bone [16]. Therefore, the higher the HA content in the composite, the higher the value of composite hardness.

Composite hardness is also affected by the degree of crystallinity of the composite. As presented in Fig. 4, the crystallinity of composites increases with increasing radiation dose. The high degree of crystallinity will make a material resistant to the solvent, making the material harder and stiffer, thus improving its wear resistance $[3,14]$. Gamma irradiation initiates chain cutting and cross-linking. Cross-linking mainly occurs in amorphous areas, improving crystallinity in those areas. On the other hand, chain cutting mostly occurs in the folds of the polymer chain producing disconnected chains in the fold area, which may play a role in the additional crystallization (thickening and refinement of lamella crystals) [6]. The level of cross-linking on the composites can be qualitatively determined by the vinylene groups absorbance in the FTIR spectrum and expressed by the vinylene index (VI). Cutting chains through homolytic cleavage can be terminated via radical recombination, forming oxide or non-oxide groups. The level of oxide group formation is expressed by the oxidation index (OI).

The VI/OI ratio was also calculated to gain more information related to the chemical processes that occurred during the irradiation. The effect of gamma radiation on VI, IO, and VI/OI ratio is shown in Fig. 6. Based on the VI, IO, and VI/OI ratio shown in Fig. 6, cross-linking is more dominant than oxidation at high doses, whereas at low doses oxidation rate is relatively dominant (see upper right panel of Fig. 6, at $25 \mathrm{kGy}$ ). This phenomenon can be explained by realizing that oxidation mainly occurs on the surface of composites, where radical oxygen is available from the bond breaking of atmospheric gas by gamma rays at low and high doses [9-10]. However, at low doses (25 kGy), the
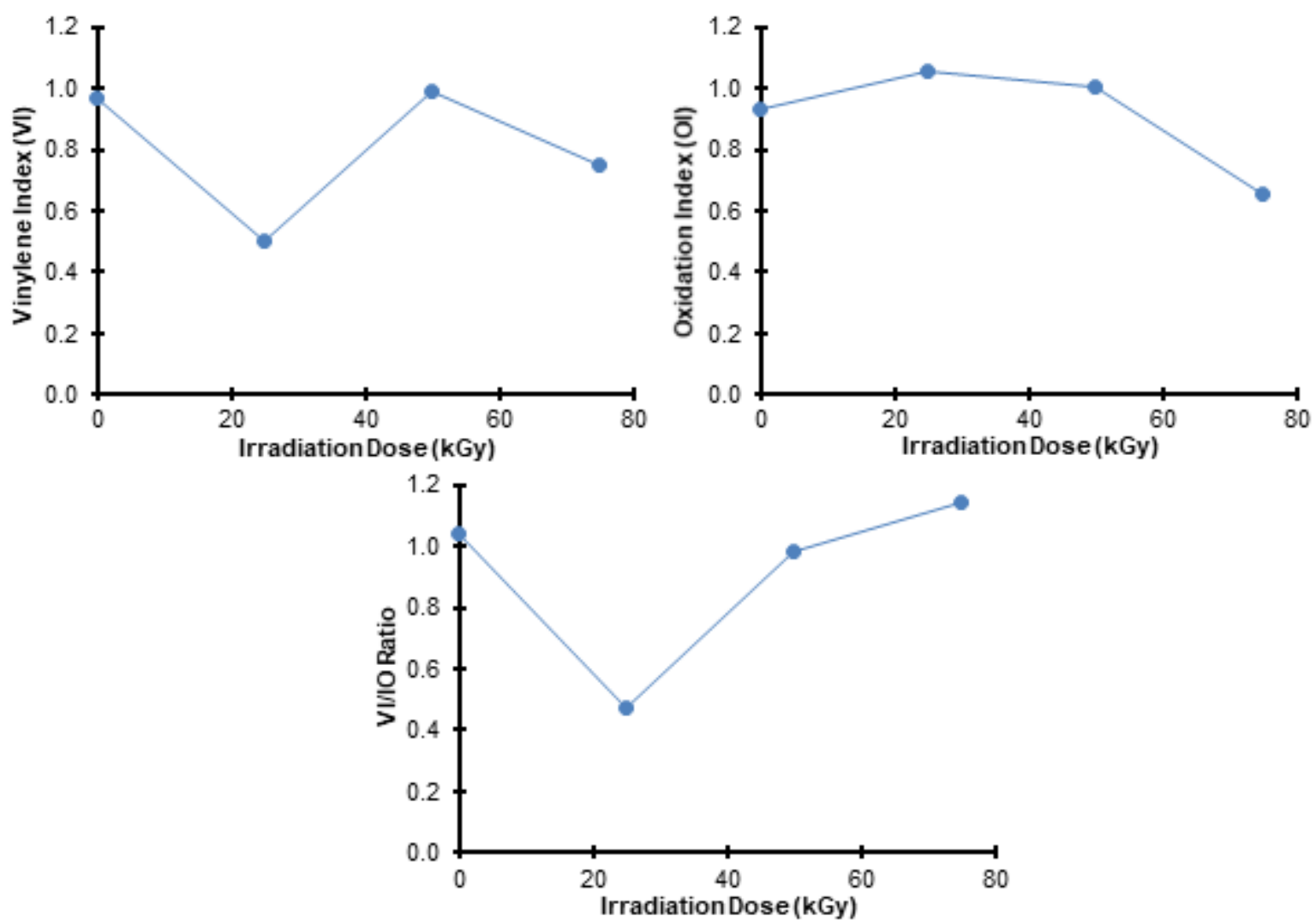

Fig 6. VI (upper left panel), OI (upper right panel), and VI/OI ratio (lower panel) of UHMWPE $+5 \%$ HA composite 
inner side of composites receives low-intensity gamma rays, so cross-linking is not very effective compared to oxidation. This explains why UHMWPE-HA composites at $25 \mathrm{kGy}$ have the lowest VI/OI ratio. The opposite result (high cross-linking) would happen if the radiation intensity received by the composites were high. Therefore, as can be seen in Fig. 6 (lower panel), composites at 50 and $75 \mathrm{kGy}$ doses have higher VI/OI ratio. The composite without gamma irradiation (0 kGy) is acting as the control.

\section{The Effect of Gamma Irradiation on Tensile Strength}

The tensile test results are reported in Fig. 7. According to Fig. 7, the maximum stress and break elongation of composites ranged from 24 to $37 \mathrm{MPa}$ and $106 \%$ to $264 \%$, respectively. The maximum stress of composites tends to decrease with increasing radiation dose (Fig. 7, left panel). Increasing radiation dose intensifies the chain cutting level (oxidative and nonoxidative) of composites. Since chain cutting plays a role in the additional crystallization (Fig. 4), it lowers the maximum stress of composites by making composites have more crystalline properties (e.g., stiff yet brittle) [6]. In general, the maximum stress values decreased as the HA percentage increased. This was caused by a decreasing amount of UHMWPE that provides bending and ductile properties. However, most of the composites had higher maximum stress than pure UHMWPE ( $0 \% \mathrm{HA})$, although the composites contained HA (Fig. 7, left panel). This shows that composite preparation and modification enhanced the maximum stress compared to pure UHMWPE.

On the other hand, break elongation of composites also decreased with increasing radiation dose (Fig. 7, right panel). This trend is related to the increasing number of cross-links relative to the oxidation rate (VI/OI ratio), as shown in Fig. 6. The high degree of crosslinks inhibits polymer chains movement when pulled, resulting in a low break elongation [21]. The $\mathrm{VI} / \mathrm{OI}$ ratio at $25 \mathrm{kGy}$ was lower than those at other doses (Fig. 6), this is why the break elongation of 5\% HA at $25 \mathrm{kGy}$ was the highest (264\%). Break elongation of composites with $5 \%$ and $10 \%$ HA was higher than pure UHMWPE ( $0 \%$ HA), yet break elongation of pure UHMWPE was still higher than the composite with $15 \%$ HA. Large amounts of HA increases the influence of HA properties (e.g., rigid, fragile) in composites [21].

\section{Physical Strength of Composite with Addition of Polyvinyl Alcohol (PVA)}

In its use as an implant, a tibial tray should not be too hard to be comfortably used for daily activity. Moreover, it should alleviate the impact and friction generated by human movements. To increase the elasticity and lubricity of material, several researchers modified the surface of the artificial joint materials with PVA [23-24]. In this study, UHMWPE-HA composites with PVA addition $(5 \% \mathrm{w} / \mathrm{w})$ were successfully prepared using mechanical alloying and hot press method. X-ray
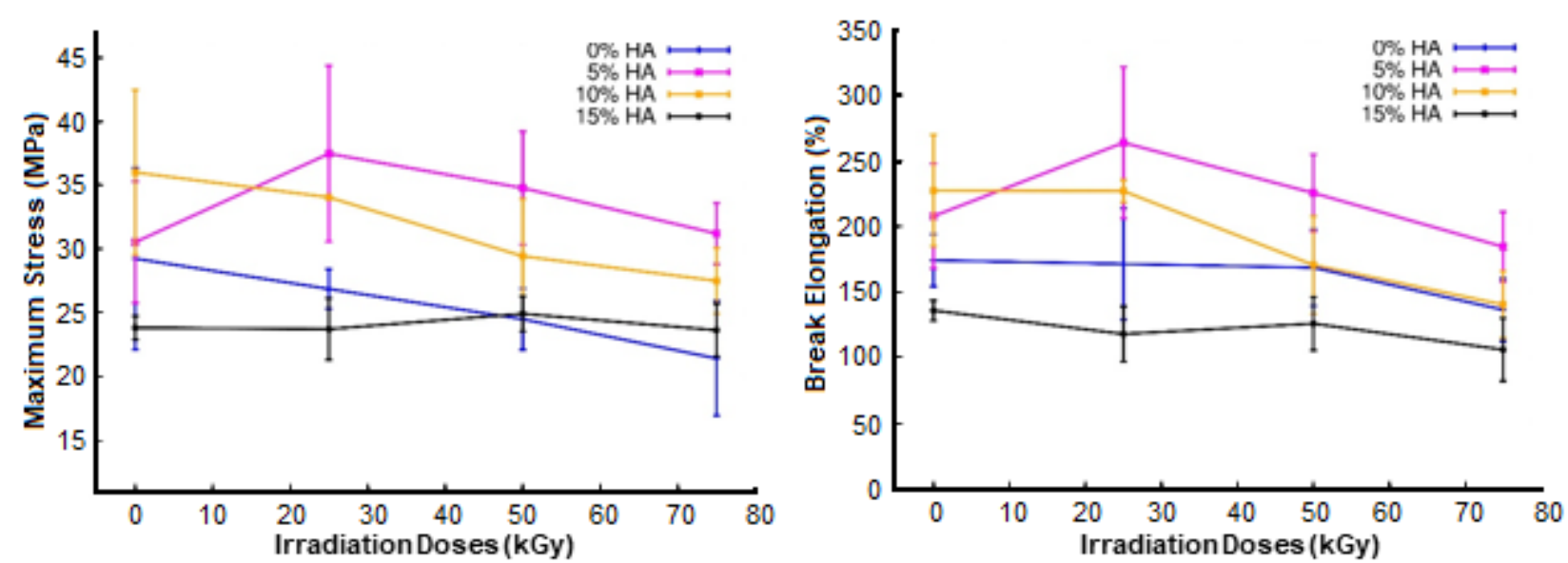

Fig 7. Maximum stress (left panel) and break elongation (right panel) of composites plotted as a function of irradiation dose 
Table 3. Lattice parameters of orthorhombic UHMWPE in composites with PVA addition

\begin{tabular}{lcccc}
\hline \multicolumn{1}{c}{ Sample } & $\mathrm{a}(\AA)$ & $\mathrm{b}(\AA)$ & $\mathrm{c}(\AA)$ & $\mathrm{V}\left(\AA^{3}\right)$ \\
\hline UHMWPE & 7.4179 & 4.9336 & 2.5425 & 93.0477 \\
UHMWPE + 5\% HA + 5\% PVA & 7.1782 & 4.8891 & 2.5257 & 88.6382 \\
UHMWPE + 15\% HA + 5\% PVA & 7.1638 & 4.9455 & 2.5438 & 90.1223 \\
\hline
\end{tabular}

Table 4. Lattice parameters of hexagonal HA in composite with PVA addition

\begin{tabular}{lccc}
\hline \multicolumn{1}{c}{ Sample } & $\mathrm{a}(\AA)$ & $\mathrm{c}(\AA)$ & $\mathrm{V}\left(\AA^{3}\right)$ \\
\hline HA & 9.3539 & 6.8797 & 521.2994 \\
UHMWPE + 15\% HA + 5\% PVA & 9.3489 & 6.8759 & 520.4495 \\
\hline
\end{tabular}

diffractograms and lattice parameters reported in Fig. 8, Table 3 and Table 4, respectively, show that all three components (UHMWPE, HA, and PVA) are physically bound.

Non-PVA composites hardness is in the range of 46 to 50 Shore D (Fig. 5), while composites with PVA had hardness values lying in the range of 42 to 48 Shore D (Fig. 9, upper panel). The hardness of composites (without and with PVA addition) was higher than pure UHMWPE. However, in composites with additional PVA, the hardness value was lower than that of composites without additional PVA. This indicates that the addition of PVA decreased the hardness level of composites, yet the hardness was still

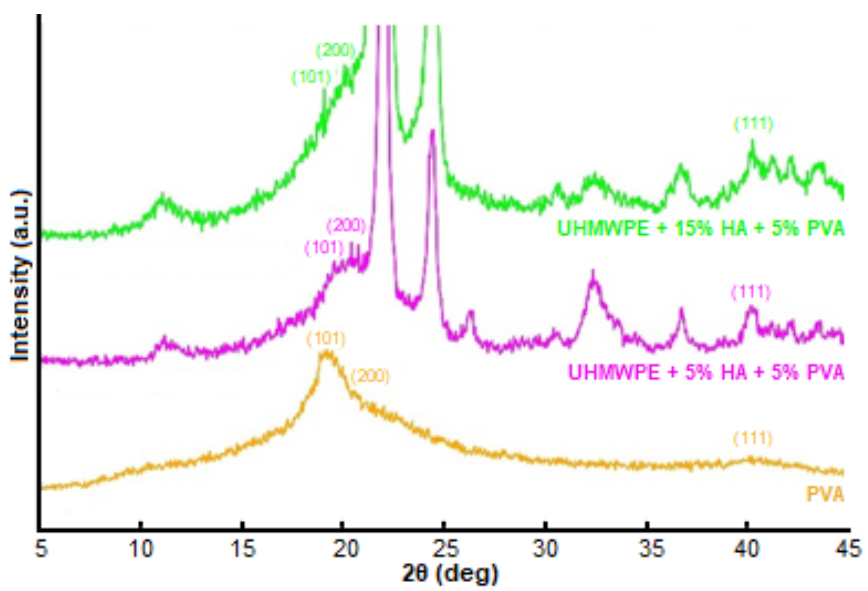

Fig 8. X-ray diffract pattern of PVA and composites with $5 \%(\mathrm{w} / \mathrm{w})$ PVA addition
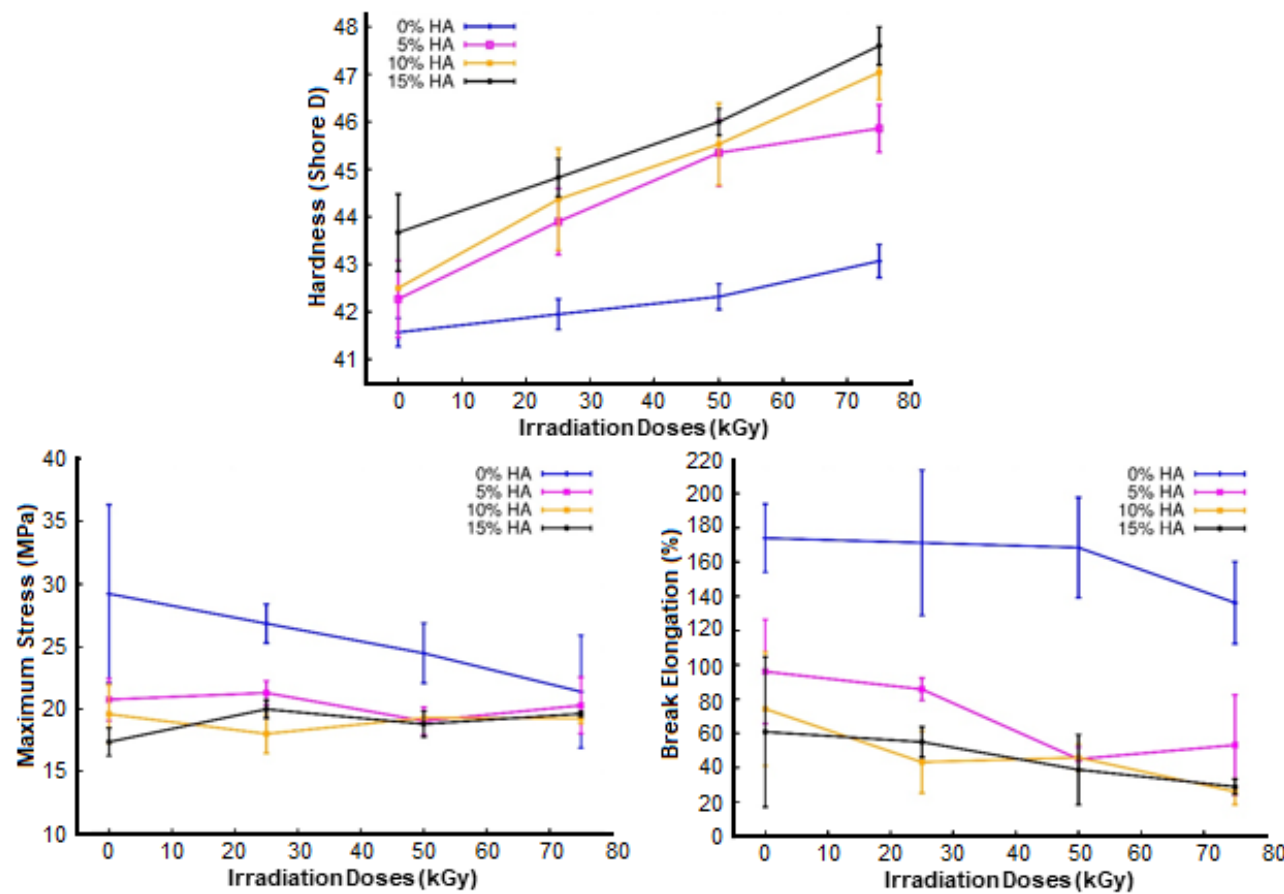

Fig 9. Hardness (upper panel), maximum stress (lower left panel) and break elongation (lower right panel) of composites with $5 \%(\mathrm{w} / \mathrm{w})$ PVA addition plotted as a function of irradiation dose 


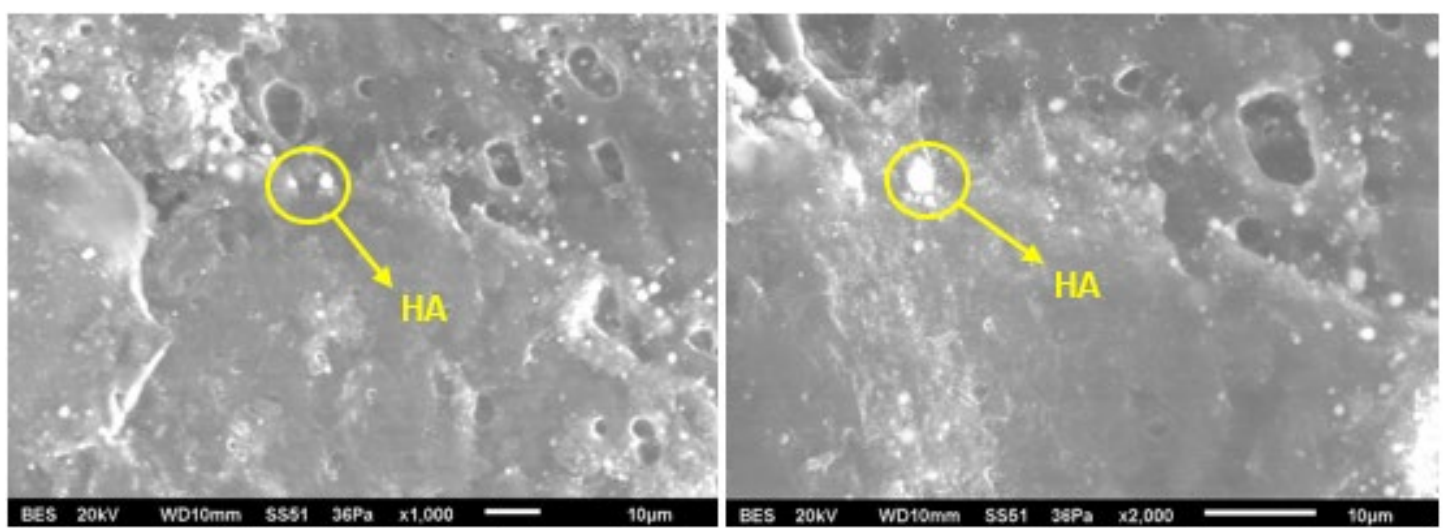

Fig 10. SEM micrographs of UHMWPE $+15 \%$ HA $+5 \%$ PVA composite with $1000 \times$ (left panel) and 2000× (right panel) magnification

higher than that of pure UHMWPE. The tensile test results of composites with PVA addition are presented in Fig. 9. Composites with PVA addition had lower maximum stress and lower break elongation compared to the pure UHMWPE. The maximum stress of composites tends to fluctuate and does not form a typical pattern (Fig. 9, left panel) while, in general, the break elongation of composites decreased with increasing radiation dose (Fig. 9 , right panel).

The lower value of maximum stress and break elongation of composites with PVA addition compared to the pure UHMWPE ( $0 \% \mathrm{HA}$ ) can be explained by looking at the SEM micrographs in Fig. 10. Addition of PVA into composites induced micropores creation on the surfaces of the composites. This phenomenon is an indication of nonhomogeneity resulting from the different polarity between UHMWPE and PVA, so both materials tend to minimize their interface area. Moreover, the physical interaction between UHMWPE and PVA is relatively weak. If homogenous composites are desired, one must go beyond mechanical alloying by employing chemical grafting on the surface of composites, in order to bind PVA with UHMWPE through a strong chemical bond [23].

\section{- CONCLUSION}

UHMWPE/HA composites were successfully synthesized using the high energy ball milling technique and hot press method. HA particles were physically bound with the UHMWPE matrix and could enhance the hardness of the polymer by $8-15 \%$ and the maximum stress up to $38 \%$. Gamma irradiation promoted crosslinking and breaking of polymer chains, represented by VI and OI, respectively, which enhanced the crystallinity by $113-172 \%$, melting point by $0.6-0.7 \%$, and decreased break elongation of composites by $23-48 \%$. Addition of PVA induced micropores creation on the surfaces of composites and thus reduced rigidity by $16-47 \%$ and hardness by $3-9 \%$.

\section{- ACKNOWLEDGMENTS}

The authors acknowledge support from the National Nuclear Energy Agency (the Center for Science and Advanced Material Technology, Puspiptek Serpong and the Center of Application of Isotopes and Radiation, Jakarta). We also thank Mr. Erizal, Mr. Bambang Sugeng, and Prof. Suminar S. Achmadi for their assistance and useful discussions during the research.

\section{- REFERENCES}

[1] Culliford, D., Maskell, J., Judge, A., Cooper, C., Prieto-Alhambra, D., and Arden, N.K., 2015, Future projections of total hip and knee arthroplasty in the UK: Results from the UK Clinical Practice Research Datalink, Osteoarthritis Cartilage, 23 (4), 594-600.

[2] Kremers, H.M., Larson, D.R., Crowson, C.S., Kremers, W.K., Washington, R.E., Steiner, C.A., Jiranek, W.A., and Barry, D.J., 2015, Prevalence of total hip and knee replacement in the United States, J. Bone Joint Surg. Am., 97 (17), 1386-1397. 
[3] Baena, J.C., Wu, J., and Peng, Z., 2015, Wear performance of UHMWPE and reinforced UHMWPE composites in arthroplasty applications: A review, Lubricants, 3 (2), 413-436.

[4] Maksimkin, A.V., Kaloshkin, S.D., Tcherdyntsev, V.V., Senatov, F.S., and Danilov, V.D., 2012, Structure and properties of ultra-high molecular weight polyethylene filled with disperse hydroxyapatite, Inorg. Mater. Appl. Res., 3 (4), 288-295.

[5] Lednický, F., Šlouf, M., Kratochvil, J., Baldrian, J., and Novotná, D., 2007, Crystalline character and microhardness of gamma-irradiated and thermally treated UHMWPE, J. Macromol. Sci. Part B Phys., 46 (3), 521-531.

[6] Slouf, M., Mikesova, J., Fencl, J., Stara, H., Baldrian, J., and Horak, Z., 2009, Impact of dose-rate on rheology, structure and wear of irradiated UHMWPE, J. Macromol. Sci. Part B Phys., 48 (3), 587-603.

[7] Kandahari, A.M., Yang, X., Laroche, K.A., Dighe, A.S., Pan, D., and Cui, Q., 2016, A review of UHMWPE wear-induced osteolysis: The role for early detection of the immune response, Bone Res., 4 , 16014.

[8] Sukaryo, S.G., Arifin, N.L., Sudaryo, S., and Sudirman, S., 2012, Pengaruh radiasi gamma terhadap sifat mekanik UHMWPE untuk tibial tray, Jurnal Kimia dan Kemasan, 34 (2), 272-281.

[9] Slouf, M., Synkova, H., Baldrian, J., Marek, A., Kovarova, J., Schmidt, P., Doschner, H., Stephan, M., and Gohs, U., 2008, Structural changes of UHMWPE after e-beam irradiation and thermal treatment, $J$. Biomed. Mater. Res. Part B, 85 (1), 240-251.

[10] Peltzer, M., Wagner, J.R., and Jiménez, A., 2007, Thermal characterization of UHMWPE stabilized with natural antioxidants, J. Therm. Anal. Calorim., 87 (2), 493-497.

[11] Selyutin, G.E., Gavrilov, Y.U., Voskresenskaya, E.N., Zakharov, V.A., Nikitin, V.E., and Poluboyarov, V.A., 2010, Composite materials based on ultra high molecular polyethylene: Properties, application prospects, Chem. Sustainable Dev., 18, 301-314.
[12] Tai, Z., Chen, Y., An, Y., Yan, X., and Xue, Q., 2012, Tribological behavior of UHMWPE reinforced with graphene oxide nanosheets, Tribol. Lett., 46 (1), 55-63.

[13] Dangsheng, X., 2005, Friction and wear properties of UHMWPE composites reinforced with carbon fiber, Mater. Lett., 59 (2-3), 175-179.

[14] Martínez-Morlanes, M.J., Castell, P., MartínezNogués, V., Martinez, M.T., Alonso, P.J., and Puértolas, J.A., 2011, Effects of gamma-irradiation on UHMWPE/MWNT nanocomposites, Compos. Sci. Technol., 71 (3), 282-288.

[15] Crowley, J., and Chalivendra, V.B., 2008, Mechanical characterization of ultra-high molecular weight polyethylene-hydroxyapatite nanocomposites, Bio-Med. Mater. Eng., 18 (3), 149160.

[16] Fang, L., Leng, Y., and Gao, P., 2006, Processing and mechanical properties of HA/UHMWPE nanocomposites, Biomaterials, 27 (20), 3701-3707.

[17] Li, F., Gao, L., Gao, H., and Cui, Y., 2017, The mechanical properties and modeling of creep behavior of UHMWPE/Nano-HA composites, $J$. Mater. Eng. Perform., 26 (9), 4514-4521.

[18] Elmkharram, H.M.A., 2013, Mechanically processed alumina reinforced ultra-high molecular weight polyethylene (UHMWPE) matrix composites, Thesis, Virginia Tech, Blacksburg, Virginia, USA.

[19] Gupta, A., Tripathi, G., Basu, B., and Balani, K., 2012, Dependence of protein adsorption on wetting behavior of UHMWPE-HA- $\mathrm{Al}_{2} \mathrm{O}_{3}-\mathrm{CNT}$ hybrid biocomposites, JOM, 64 (4), 506-513.

[20] Gupta, A., Tripathi, G., Lahiri, D., and Balani, K., 2013, Compression molded ultra high molecular weight polyethylene-hydroxyapatite-aluminum oxide-carbon nanotube hybrid composites for hard tissue replacement, J. Mater. Sci. Technol., 29 (6), 514-522.

[21] Alothman, O.Y., Almajhdi, F.N., and Fouad, H., 2013, Effect of gamma radiation and accelerated aging on the mechanical and thermal behavior of 
HDPE/HA nano-composites for bone tissue regeneration, Biomed. Eng. Online, 12, 95.

[22] Kang, X., Zhang, W., and Yang, C., 2016, Mechanical properties study of micro-and nano-hydroxyapatite reinforced ultrahigh molecular weight polyethylene composites, J. Appl. Polym. Sci., 133 (3), 42869.

[23] Chen, K., Zhang, D., Cui, X., and Wang, Q., 2015,
Preparation of ultrahigh-molecular-weight poly ethylene grafted with polyvinyl alcohol hydrogel as an artificial joint, RSC Adv., 5 (31), 24215-24223.

[24] Omata, S., Sawae, Y., and Murakami, T., 2015, Effect of poly(vinyl alcohol) (PVA) wear particles generated in water lubricant on immune response of macrophage, Biosurf. Biotribol., 1 (1), 71-79. 